\title{
Prospective study of grapefruit intake and risk of breast cancer in postmenopausal women: the Multiethnic Cohort Study
}

\author{
KR Monroe*,I, SP Murphy², LN Kolonel² and MC Pike' \\ 'Department of Preventive Medicine, Keck School of Medicine, University of Southern California, Los Angeles, CA 90089-9175, USA; ${ }^{2}$ Cancer Research \\ Center of Hawaii, University of Hawaii, Honolulu, HI 96813, USA
}

In vitro and in vivo studies have shown that cytochrome P450 3A4 (CYP3A4) is involved in the metabolism of oestrogens. There is evidence that grapefruit, an inhibitor of CYP3A4, increases plasma oestrogen concentrations. Since it is well established that oestrogen is associated with breast cancer risk, it is plausible that regular intake of grapefruit would increase a woman's risk of breast cancer. We investigated the association of grapefruit intake with breast cancer risk in the Hawail-Los Angeles Multiethnic Cohort Study, a prospective cohort that includes over 50000 postmenopausal women from five racial/ethnic groups. A total of I 657 incident breast cancer cases were available for analysis. Grapefruit intake was significantly associated with an increased risk of breast cancer (relative risk $=1.30,95 \%$ confidence interval 1.06-1.58) for subjects in the highest category of intake, that is, one-quarter grapefruit or more per day, compared to non-consumers $\left(P_{\text {trend }}=0.015\right)$. An increased risk of similar magnitude was seen in users of oestrogen therapy, users of oestrogen + progestin therapy, and among never users of hormone therapy. Grapefruit intake may increase the risk of breast cancer among postmenopausal women.

British Journal of Cancer (2007) 97, 440-445. doi: I 0.1038/sj.bjc.6603880 www.bjcancer.com

Published online 10 July 2007

(c) 2007 Cancer Research UK

Keywords: breast cancer; grapefruit intake; CYP3A4 metabolism

The inhibitory effect of grapefruit juice on the intestinal cytochrome P450 3A4 (CYP3A4) system was discovered accidentally in 1989 during a study designed to test the effect of ethanol on a calcium-channel blocker (Bailey et al, 1989, 1991). Grapefruit juice was given to subjects to mask the taste of ethanol. Subsequent investigations found that through the inhibition of the CYP3A4 enzyme system, primarily in the liver and small intestine (Guengerich, 1999; Veronese et al, 2003), grapefruit juice interacts with more than $60 \%$ of orally administered drugs leading to elevation of their serum concentrations (Maskalyk, 2002; Bailey and Dresser, 2004). Consumption of a single glass (six ounces) can produce the maximal acute pharmacokinetic effect (Edgar et al, 1992; Lundahl et al, 1995, 1997; Dahan and Altman, 2004) with enhanced oral drug bioavailability occurring up to $24 \mathrm{~h}$ after juice consumption (Bailey and Dresser, 2004).

Since 1989, the list of drug interactions with grapefruit juice has expanded to include oral $17 \beta$-oestradiol and progesterone (Guengerich, 1999; Maskalyk, 2002; Medical Letter, 2005). The US Food and Drug Administration (FDA) mandated labelling for hormone products for postmenopausal women now contains warnings that grapefruit juice may increase plasma concentrations of oestrogen (US Food and Drug Administration, 2006). Schubert et al (1994) found that grapefruit juice increased the area under the

* Correspondence: Dr KR Monroe, USC/Norris Comprehensive Cancer Center, I44I Eastlake Avenue (MS\#44), Los Angeles, CA 90089-9175, USA; E-mail: kmonroe@usc.edu

Received 30 April 2007; revised II June 2007; accepted I9 June 2007; published online 10 July 2007 curve of oestradiol approximately $20 \%$ in ovariectomised women Recently, we reported that endogenous oestrogen levels were about $30 \%$ higher in postmenopausal women in whom periods had stopped naturally and who were consuming the equivalent of $\frac{1}{4}$ grapefruit or more per day (Monroe et al, 2007).

It is well established that oestrogen is associated with breast cancer risk (Key et al, 2002). Therefore, if grapefruit intake affects oestrogen metabolism leading to higher circulating levels, then it is biologically plausible that regular intake of grapefruit would increase a woman's risk of breast cancer. To our knowledge, no study has yet examined this hypothesis. The present study investigated the association of grapefruit intake and breast cancer risk in the Hawaii-Los Angeles Multiethnic Cohort (MEC) Study.

\section{MATERIALS AND METHODS}

\section{Study population}

The MEC was assembled in 1993-1996 when 96810 adult men and 118441 adult women, aged $45-75$ at baseline, completed a 26page, self-administered mailed questionnaire that contained a quantitative food frequency questionnaire (FFQ) and information on demographic factors, personal behaviours, prior medical conditions, use of medications, family history of common cancers, and, for women, reproductive history and use of oral contraceptives and hormone therapy (HT). The study was approved by the Institutional Review Boards of the University of Hawaii and the University of Southern California. Further details regarding the study have been given elsewhere (Kolonel et al, 2000). 
Only women from the five racial/ethnic groups - African Americans, Japanese Americans, Latinas, Native Hawaiians, and Caucasians - were included in the study reported here. Also we only included women who reported that their menstrual periods had stopped naturally or due to oophorectomy. Women who had undergone hysterectomy but reported one or more ovaries still intact were excluded. We also excluded women with missing or invalid data for weight, height, oestrogen and/or progestin use, age at menarche, parity, age at first live birth, age at natural menopause or age at bilateral oophorectomy, physical activity, smoking status, or education level. We also excluded subjects if they had been diagnosed with cancer other than non-melanoma skin cancer before cohort entry. Finally, we excluded subjects if their intake of calories or its components (fat, protein, and carbohydrate) from the baseline FFQ fell outside a defined valid range (Nothlings et al, 2005). As a result, data for 46080 postmenopausal women were available for analysis.

\section{Surveillance}

Incident cases of breast cancer in California were identified by linkage to the Los Angeles County SEER registry and to the State of California Cancer Registry (CCR). Incident cancers in Hawaii were identified using the statewide Hawaii SEER registry and the CCR was used to identify cases who had moved to California. A software program was used to conduct a probabilistic data linkage using social security number, name, and date of birth. We had a social security number on $98.7 \%$ of the cohort. Further, we determined that after an average period of 7 years in the cohort, the outmigration rate was $3.7 \%$ (4.9\% for Hawaii participants and $2.5 \%$ for California participants). Although the out-migration rate is somewhat higher for Hawaii, California is the primary destination for these migrants, so that most remain under surveillance for cancer incidence. Mortality was determined by annual linkage to state death files in California and Hawaii, and periodically to the National Death Index. Follow-up time began on the date the respondent completed the baseline questionnaire and, for the analysis reported here, continued through 31 December 2002. Subjects were censored at the date of last follow-up, date of death, or date of diagnosis of cancer, whichever occurred earlier.

\section{Assessment of grapefruit intake from baseline questionnaire}

The methods for dietary assessment have been described in detail elsewhere (Kolonel et al, 2000). The FFQ asked respondents to report how often they ate 'grapefruit or pomelo' during the past year and the usual portion size. Usual intake was reported by marking one of the following eight frequencies: never or hardly ever; once a month; $2-3$ times a month; once a week; $2-3$ times a week; 4-6 times a week; once a day; 2 or more times a day. Portion sizes for whole grapefruit included $\frac{1}{4}$ cup or less, $\frac{1}{2}$ grapefruit or $\frac{1}{2}$ cup, and 1 cup or more. The average weight of one grapefruit was estimated to be $240 \mathrm{~g}$. Total grapefruit intake was calculated by multiplying the frequency and portion size and expressed as grams per day. We were unable to quantify intake of grapefruit juice as it was combined with orange juice in the FFQ. The performance of the FFQ in a calibration sub-study has been previously reported (Stram et al, 2000).

\section{Menopausal hormone therapy use from baseline questionnaire}

Subjects were asked about use of menopausal oestrogen therapy (ET) and progestin therapy (PT) separately in the baseline questionnaire. Oestrogen + progestin therapy (EPT) was calculated based on the overlap between reported periods of ET and PT use (Lee et al, 2006). For the present analysis, we used a categorical variable defined as follows: (1) no HT use; (2) past HT use; (3) current ET use; and (4) current EPT use.

\section{Statistical analysis}

Hazard ratios for breast cancer incidence, referred to in this report as relative risks (RRs), were estimated using log-linear regression proportional hazard models stratified on age at recruitment (single year), year of recruitment (single year), race/ethnicity (African American, Japanese, US-born Latina, Latina born in Mexico or other Central or South American country, Native Hawaiian, and Caucasian), and study centre (Hawaii/California). We examined grapefruit intake by categories of both absolute intake (none, $<30 \mathrm{~g},<60 \mathrm{~g}$, and $\geqslant 60 \mathrm{~g}$ ) and intake per $1000 \mathrm{kcal}$ (none, $<15$, $<30$, and $\geqslant 30 \mathrm{~g}$ per $1000 \mathrm{kcal}$ ). The highest category of absolute intake $(\geqslant 60 \mathrm{~g})$ was an average of slightly greater than $\frac{1}{4}$ grapefruit per day or $\frac{1}{2}$ every other day. The highest category of intake density was roughly equivalent. Categories were determined by usual serving size (as defined above) from the FFQ and the intake distribution for all subjects. Non-dietary factors considered as potential confounders included age at menarche $(\leqslant 12,13-14$, and $15+)$, age at first live birth $(\leqslant 20,21-30$, and $31+)$, parity (nulliparous, 1 child, $2-3$ children, and $4+$ children), age at and type of menopause (natural menopause at age $<45,45-49,50-54$, and $55+$ or oophorectomy at age $<45,45-49$, and $50+$ ), postmenopausal oestrogen and/or progestin use (as defined above), weight (continuous) and height (continuous) at recruitment, physical activity (continuous variable for hours per day engaged in vigorous work and/or strenuous exercise), family (mother or sister) history of breast cancer (yes/no), education level attained ( $\leqslant 10$ th grade, high school, some college or vocational school, and college graduate), and smoking status at baseline (never, former, and current). Dietary factors considered as potential confounders included intakes of alcohol, total energy, saturated fat, total dietary fibre, and soluble and insoluble fibre fractions. The dietary fibre value used in the present study is that published in the USDA tables and is the sum of lignin and nonstarch polysaccharides in plant foods (Prosky et al, 1985). The values for insoluble and soluble fractions were obtained by the Englyst procedure, which aims to measure plant cell wall nonstarch polysaccharides as the sum of the chemically identified constituent sugars; the procedure does not measure lignin (Englyst et al, 1994). Although these two methods of fibre analysis are highly correlated, they are nevertheless distinct from one another and may not be combined. The variables included in the final multivariate model were established risk factors and factors we had found to influence serum oestrogen levels in our previous study (Monroe et al, 2007), that is, dietary fibre and soluble fibre intakes. The underlying time variable in the analysis was time from the date of cohort enrollment to the date of breast cancer diagnosis, death, or censoring.

Calculations were performed using the SAS (SAS Institute, Cary, NC, USA) and STATA (Stata Corporation, College Station, TX, USA) statistical software packages. Testing for significance was performed using likelihood ratio methods. All $P$-values quoted are two-sided.

\section{RESULTS}

A total of 1657 of the women in the defined cohort were diagnosed with incident breast cancer before 31 December 2002 and are included in the analysis. Some baseline characteristics of the breast cancer cases and the total study population are shown in Table 1. Japanese Americans comprise the largest group with $32 \%$ of the population followed by Caucasians with 26\%. Overall, whole grapefruit was consumed by $50 \%$ of the study population with $7 \%$ reporting intake of $\frac{1}{4}$ grapefruit or more per day. Grapefruit was 
Table I Baseline characteristics of breast cancer cases and the total study population

\begin{tabular}{|c|c|c|}
\hline & Cases & Total population \\
\hline No. of subjects & 1657 & 46080 \\
\hline Age at cohort entry (in years), mean (s.d.) & $62.1(7.27)$ & $61.5(7.35)$ \\
\hline Body mass index, mean (s.d.) & $25.5(5.20)$ & $25.6(5.28)$ \\
\hline \multicolumn{3}{|l|}{ Race/ethnicity } \\
\hline African American & 253 & 8,398 \\
\hline Japanese American & 579 & 14906 \\
\hline Latina & 248 & 8404 \\
\hline Native Hawaiian & 144 & 2608 \\
\hline Caucasian & 433 & 11764 \\
\hline \multicolumn{3}{|l|}{ Education } \\
\hline$\leqslant 10$ th grade & 217 & 7063 \\
\hline High school & 487 & 14183 \\
\hline Some college or vocation school & 482 & 13585 \\
\hline College graduate & 471 & 11249 \\
\hline \multicolumn{3}{|l|}{ Age at menarche } \\
\hline$\leqslant 12$ & 834 & 22138 \\
\hline $13-14$ & 642 & $|8| 5 \mid$ \\
\hline $15+$ & 181 & $579 \mid$ \\
\hline \multicolumn{3}{|l|}{ Age at first live birth } \\
\hline Never & 271 & 5939 \\
\hline$\leqslant 20$ & 343 & 12046 \\
\hline $21-30$ & 888 & 24923 \\
\hline $31+$ & 155 & 3172 \\
\hline \multicolumn{3}{|l|}{ Parity } \\
\hline Nulliparous & 271 & 5939 \\
\hline I child & 202 & 5012 \\
\hline $2-3$ children & 750 & 20537 \\
\hline $4+$ children & 434 & 14592 \\
\hline \multicolumn{3}{|l|}{ Type of and age at (in years) menopause } \\
\hline Natural, $<45$ & 167 & 5346 \\
\hline Natural, $45-49$ & 392 & 11177 \\
\hline Natural, 50-54 & 601 & 15612 \\
\hline Natural, 55+ & 198 & 4148 \\
\hline Oophorectomy, $<45$ & 152 & 5395 \\
\hline Oophorectomy, $45-49$ & 92 & 2898 \\
\hline Oophorectomy, 50+ & 55 & 1504 \\
\hline \multicolumn{3}{|l|}{ Postmenopausal HT use } \\
\hline Never & 631 & 20959 \\
\hline Former HT use & 259 & 8436 \\
\hline Current ET use & 207 & 5843 \\
\hline Current EPT use & 560 & 10842 \\
\hline \multicolumn{3}{|l|}{ Smoking status } \\
\hline Never smoker & 908 & 25938 \\
\hline Former smoker & 535 & 13811 \\
\hline Current smoker & 214 & 6331 \\
\hline \multicolumn{3}{|l|}{ Family history of breast cancer } \\
\hline Yes & 271 & 5005 \\
\hline No & 1386 & 41075 \\
\hline \multicolumn{3}{|l|}{ Alcohol intake } \\
\hline None & 977 & 28556 \\
\hline$<12$ g per day (one drink) & 466 & 12876 \\
\hline$<24$ g per day & 82 & 2108 \\
\hline$\geqslant 24 \mathrm{~g}$ per day & 132 & 2540 \\
\hline \multicolumn{3}{|l|}{ Grapefruit intake } \\
\hline None & 794 & 23203 \\
\hline$<30$ g per day & 635 & 16911 \\
\hline$<60$ g per day & 95 & 2692 \\
\hline$\geqslant 60$ g per day ( $\frac{1}{4}$ grapefruit) & 133 & 3274 \\
\hline
\end{tabular}

consumed by $55 \%$ of Japanese Americans, $51 \%$ of African Americans, $49 \%$ of Caucasians, $45 \%$ of Latinas, and $35 \%$ of Hawaiian study subjects.

Table 2 shows the risk of breast cancer across category of grapefruit intake quantified by absolute intake (g) and by intake density ( $g$ per $1000 \mathrm{kcal})$. The first relative risk $\left(\mathrm{RR}_{1}\right)$ estimate was adjusted for (stratified on) age at recruitment, year of recruitment, race/ethnicity, and study centre. Intake of $\frac{1}{4}$ grapefruit or more per day is associated with a $21 \%$ increase in breast cancer risk $\left(\mathrm{RR}_{1}=1.21,95 \%\right.$ confidence interval $(\mathrm{CI})=1.00-1.46, P_{\text {trend }}=$ $0.044)$; the highest category of grapefruit density ( $\geqslant 30 \mathrm{~g}$ per $1000 \mathrm{kcal})$ is also associated with increased breast cancer risk $\left(\mathrm{RR}_{1}=1.18\right.$, $\left.95 \% \mathrm{CI}=0.98-1.42, P_{\text {trend }}=0.040\right)$. Second relative risk $\left(\mathrm{RR}_{2}\right)$ estimate was adjusted (stratified) as above, and further adjusted for weight, height, physical activity, education, age at menarche, age at first birth, parity, age at and type of menopause, menopausal oestrogen/progestin use, cigarette smoking, family history of breast cancer, alcohol, saturated fat, total dietary fibre, and soluble fibre. With these adjustments, intake of $\frac{1}{4}$ grapefruit or more per day is significantly associated with a $30 \%$ increase in breast cancer risk $\left(\mathrm{RR}_{2}=1.30,95 \% \mathrm{CI}=1.06-1.58, P_{\text {trend }}=0.015\right)$; the highest category of grapefruit density is likewise associated with a $25 \%$ increase in breast cancer risk $\left(\mathrm{RR}_{2}=1.25,95 \% \mathrm{CI}=1.03-1.52\right.$, $\left.P_{\text {trend }}=0.013\right)$. The increase in $R R$ from $R_{1}$ to $R R_{2}$ was due to adjustment for total dietary fibre and soluble fibre; adjustment for insoluble and soluble fibre produced almost identical results (data not shown).

The associations between grapefruit intake and breast cancer risk by category of HT use are shown in Table 3 . The reference category for all RR estimates is never HT/non-consumers of grapefruit. Because the results for grapefruit intake density were similar to results for absolute intake, we present only the latter. Among never HT users, there is a statistically significant positive association between the highest category of grapefruit intake $(\geqslant 60 \mathrm{~g}$ per day) and breast cancer risk $(\mathrm{RR}=1.44,95 \% \mathrm{CI}=1.08-$ $\left.1.93, P_{\text {trend }}=0.038\right)$. There is no trend among past HT users. For current ET users, there is an increase in risk of $36 \%$ from the lowest (zero) category of intake to the highest $\left(P_{\text {trend }}=0.22\right)$; for current EPT users, breast cancer risk increases $27 \%$ from the lowest to the highest category of grapefruit intake $\left(P_{\text {trend }}<0.13\right)$. There was a dose-response relationship between grapefruit intake and breast cancer risk in never HT users and in current ET and EPT users. Although the trend tests are not significant for current ET and EPT users, the pattern is the same in the three groups, and there is no statistical evidence that the magnitudes of the trends differ.

We examined whether the association of grapefruit intake and breast cancer risk was modified by body mass index (BMI: weight in kilograms/(height in metres) ${ }^{2}$ ). Subjects were divided into two categories: lean/normal weight $(\mathrm{BMI}<25.0)$ and overweight/obese $(\mathrm{BMI} \geqslant 25.0)$. The association between grapefruit intake and breast cancer risk was not modified by BMI, as shown in Table 4 . The reference category for all $\mathrm{RR}$ estimates is $\mathrm{BMI}<25.0 /$ nonconsumers of whole grapefruit. Among lean/normal weight subjects, there is a statistically significant increased risk of breast cancer associated with grapefruit intake. Risk increases 32\% from the lowest (zero) category of intake to the highest $\left(P_{\text {trend }}=0.011\right)$. Among overweight/obese subjects, breast cancer risk increases $26 \%$ from the lowest to the highest category ( $R R=1.46,95 \%$ $\mathrm{CI}=1.10-1.96)$, although the test for trend is not statistically significant.

\section{DISCUSSION}

To our knowledge, this is the first report of a commonly consumed food that may increase the risk of breast cancer among postmenopausal women. Whole grapefruit intake was significantly 
Table 2 Relative risks (with 95\% confidence intervals) of breast cancer across categories ${ }^{\text {a }}$ of grapefruit intake

\begin{tabular}{|c|c|c|c|c|c|}
\hline \multicolumn{6}{|c|}{ Grapefruit (g per day) } \\
\hline Intake & None & $>0$ to $<30 \mathrm{~g}$ & $\geqslant 30$ to $<60 \mathrm{~g}$ & $\geqslant 60 \mathrm{~g}$ & $P_{\text {trend }}$ \\
\hline Adjusted $\mathrm{RR}_{\mathrm{I}}$ & 1.00 & $1.08(0.97-1.21)$ & $1.04(0.83-1.29)$ & $1.21(1.00-1.46)$ & 0.044 \\
\hline \multicolumn{6}{|c|}{ Grapefruit (g per $1000 \mathrm{kcal}$ per day) } \\
\hline Intake & None & $>0$ to $<15 g$ & $\geqslant 15$ to $<30 \mathrm{~g}$ & $\geqslant 30 \mathrm{~g}$ & - \\
\hline No. of cases & 794 & 632 & 93 & 138 & - \\
\hline Adjusted $\mathrm{RR}_{\mathrm{I}}$ & 1.00 & $1.08(0.97-1.20)$ & $1.12(0.90-1.40)$ & $1.18(0.98-1.42)$ & 0.040 \\
\hline
\end{tabular}

$R R_{1}=$ first relative risk: $R R_{2}=$ second relative risk. $R R_{1}$ stratified on age at recruitment, year of recruitment, race/ethnicity, and study centre. $R R_{2}$ stratified as above and adjusted for weight, height, physical activity, age at menarche, age at first birth, parity, age at and type of menopause, oestrogen and/or progestin use, smoking, education, family history of breast cancer, alcohol, total energy, saturated fat (g per $1000 \mathrm{kcal})$, dietary fibre (g per $1000 \mathrm{kcal})$, and soluble fibre ( $\mathrm{g}$ per $1000 \mathrm{kcal})$. ${ }^{\mathrm{a} C a t e g o r i e s ~ f o r ~ g r a p e f r u i t ~ i n t a k e ~ a r e ~ b a s e d ~}$ on total grams for I grapefruit $=240 \mathrm{~g}$ per day. The highest category therefore represents $\frac{1}{4}$ grapefruit every day or $\frac{1}{2}$ every other day.

Table 3 Relative risks (with 95\% confidence intervals) of breast cancer across categories ${ }^{\mathrm{a}}$ of grapefruit intake by HT use

\begin{tabular}{|c|c|c|c|c|c|}
\hline Grapefruit (g per day) & 0 & $>0$ to $<30 \mathrm{~g}$ & $\geqslant 30$ to $<60 \mathrm{~g}$ & $\geqslant 60 \mathrm{~g}$ & $P_{\text {trend }}$ \\
\hline \multicolumn{6}{|l|}{ Never HT } \\
\hline No. of cases & 298 & 244 & 30 & 59 & 一 \\
\hline Adjusted $\mathrm{RR}_{\mathrm{I}}$ & 1.00 & $1.19(1.00-1.41)$ & $0.87(0.59-1.27)$ & $1.44(1.08-1.93)$ & 0.038 \\
\hline \multicolumn{6}{|l|}{ Past HT } \\
\hline No. of cases & 133 & 91 & 17 & 18 & - \\
\hline Adjusted $\mathrm{RR}_{\mathrm{I}}$ & $1.22(0.99-1.50)$ & $1.13(0.88-1.43)$ & $1.44(0.87-2.37)$ & $1.17(0.72-1.92)$ & 0.97 \\
\hline Adjusted $\mathrm{RR}_{\mathrm{I}}$ & $1.56(1.21-2.01)$ & $1.70(1.29-2.23)$ & $1.85(1.06-3.25)$ & $2.12(1.29-3.49)$ & 0.22 \\
\hline \multicolumn{6}{|l|}{ Current EPT } \\
\hline No. of cases & 238 & 191 & 29 & 34 & - \\
\hline Adjusted $\mathrm{RR}_{\mathrm{I}}$ & $2.01(1.69-2.40)$ & $2.09(|.73-2.5|)$ & $2.48(1.72-3.58)$ & $2.55(1.80-3.63)$ & 0.13 \\
\hline
\end{tabular}

Table 4 Relative risks (with 95\% confidence intervals) of breast cancer across categories ${ }^{\mathrm{a}}$ of grapefruit intake by BMI

\begin{tabular}{|c|c|c|c|c|c|}
\hline Grapefruit (g per day) & 0 & $>0$ to $<30 \mathrm{~g}$ & $\geqslant 30$ to $<60 \mathrm{~g}$ & $\geqslant 60 \mathrm{~g}$ & $P_{\text {trend }}$ \\
\hline \multicolumn{6}{|l|}{$B M l<25.0$} \\
\hline No. of cases & 407 & 339 & $\begin{array}{r}55 \\
-(4)-(5)\end{array}$ & 74 & \\
\hline Adjusted RR I & & & & & 0.011 \\
\hline \multicolumn{6}{|l|}{$B M I \geqslant 25$} \\
\hline No. of cases & 387 & 296 & 40 & 59 & \\
\hline Adjusted $\mathrm{RR}_{\mathrm{I}}$ & $1.16(1.00-1.34)$ & $1.30(1.11-1.52)$ & $1.16(0.83-1.62)$ & $1.46(1.10-1.96)$ & 0.113 \\
\hline
\end{tabular}

$\mathrm{BMI}=$ body mass index; $\mathrm{RR}_{\mathrm{I}}=$ first relative risk. $\mathrm{RR}$, stratified on age at recruitment, year of recruitment, race/ethnicity, and study centre and adjusted for oestrogen/progestin use, physical activity, education, age at menarche, age at first birth, parity, age at and type of menopause, smoking, family history of breast cancer, alcohol, total energy, saturated fat (g per $1000 \mathrm{kcal})$, dietary fibre $(\mathrm{g}$ per $1000 \mathrm{kcal})$, and soluble fibre $(\mathrm{g}$ per $1000 \mathrm{kcal})$ ) ${ }^{\mathrm{a}}$ Categories for grapefruit intake are based on total grams for one grapefruit = $240 \mathrm{~g}$ per day. The highest category therefore represents $\frac{1}{4}$ grapefruit every day or $\frac{1}{2}$ every other day.

associated with breast cancer in the present study - generally, a $30 \%$ increase among subjects who consume the equivalent of $\frac{1}{4}$ grapefruit or more per day.

To reduce measurement error in dietary assessments, investigators often energy-adjust intakes by calculating densities, that is, g per $1000 \mathrm{kcal}$ of total energy intake. Densities represent the contribution of a particular nutrient or food group in relation to overall dietary intake as measured by the FFQ (Willett, 1998). However, individual food intakes, particularly with respect to fruits and vegetables, are also commonly examined in terms of absolute or crude intake (van Gils et al, 2005). The biologic implication of the two analytic approaches needs careful consideration when interpreting diet-disease associations (Willett, 1998). We considered this issue in our data and found that both approaches produced similar results. We present the detailed results in terms of absolute intake to make them more easily interpretable.

The measure of grapefruit intake in the present study, based on intake of the whole fruit, is an underestimation of total intake owing to a lack of information on grapefruit juice. If one makes the assumption that grapefruit juice intake is highly correlated with whole fruit intake, then the magnitude of risk observed in the 
present study is biased upwards; it represents the risk of breast cancer owing to total intake not just whole fruit intake. However, if there is little correlation between whole grapefruit and grapefruit juice intakes, and if one accepts that grapefruit juice intake increases breast cancer risk in the same manner as the whole fruit, then the magnitude of risk observed in the present study may be an underestimation of the true risk. This requires further study.

Beginning in the 1980s, it was hypothesised that dietary fibre may have a beneficial effect on breast cancer incidence by lowering endogenous oestrogen levels through the partial interruption by dietary fibre of the enterohepatic recirculation of oestrogens (Goldin et al, 1982, 1986; Adlercreutz, 1990). While recent epidemiological evidence supports a role for dietary fibre intake in relation to lower endogenous hormone levels (Rock et al, 2004; Prentice et al, 2006), the question remains unsettled. In our study of endogenous oestrogen levels in postmenopausal women, oestradiol decreased monotonically from 10.6 to $6.2 \mathrm{pg} \mathrm{ml}^{-1}$ from the lowest to the highest quintile of dietary fibre intake (median intake of 9.9-21.7 g per $1000 \mathrm{kcal}$ ), whereas soluble fibre, after adjustment for dietary fibre, was associated with an increase in oestradiol from 6.8 to $11.5 \mathrm{pg} \mathrm{ml}^{-1}$ from the lowest to the highest quintile of intake (median intake of $2.9-7.1 \mathrm{~g}$ per $1000 \mathrm{kcal}$ ) (Monroe et al, 2007). Taken together, these results suggested that the component of total dietary fibre not accounted for by soluble and insoluble fibre was strongly negatively associated with serum oestradiol while soluble fibre increased oestradiol levels. This is complex as most plant foods contain a mixture of soluble and insoluble fibre, as well as other constituents. We hypothesised that the result for total dietary fibre represented high lignin-containing foods as lignin is the primary constituent of dietary fibre not accounted for by soluble and insoluble fibre. Further, there is evidence that lignin adsorbs oestrogen, more so than other fibre components (Shultz and Howie, 1986; Arts et al, 1991).

In the present study, the addition of total dietary fibre and soluble fibre to the statistical model modified the estimate of breast cancer risk associated with grapefruit intake $\left(R_{1}\right.$ to $R_{2}$ in Table 2). On the basis of our observation that intakes of total dietary fibre and soluble fibre are significantly associated with serum oestrogen levels in naturally postmenopausal women, and the in vitro evidence that certain fibre components, particularly lignin, have the ability to adsorb oestrogen, the adjustment will provide a more accurate estimate of breast cancer risk associated with grapefruit intake.

Consistent with other studies on postmenopausal oestrogen use, we found an increase in breast cancer risk, particularly among current EPT users. One aim of our study was to examine the risk of breast cancer associated with grapefruit intake by subgroup of menopausal HT use. As endogenous oestrogens are metabolised in the same manner as exogenous estrogens (US Food and Drug Administration, 2006), we had hypothesised that grapefruit intake would increase a woman's risk of breast cancer, regardless of HT use. Support for the hypothesis among women taking HT was provided by the warning in FDA mandated labelling of menopausal HT products that grapefruit juice may increase plasma concentrations of oestrogens.

The association between grapefruit intake and breast cancer risk was clearly seen in never HT users, as well as current ET and EPT users. Interestingly, the $\mathrm{RR}$ of breast cancer associated with consumption of $\frac{1}{4}$ grapefruit or more per day compared to nonconsumers was $44 \%$ higher among women who had never used HT, $36 \%$ higher in current ET users, and $27 \%$ higher among current EPT users. The risk of breast cancer associated with consumption of grapefruit was 32\% higher among lean/normal weight women and $26 \%$ higher among overweight/obese women. Taken together, these results for HT and BMI suggest that the risk of breast cancer associated with grapefruit intake is stronger for subgroups of women with lower circulating oestrogen levels.
This finding of a reduced effect of grapefruit in women with a higher BMI is similar to the lower effect of ET on breast cancer risk in women with a higher BMI (Collaborative Group on Hormonal Factors in Breast Cancer, 1997; Schairer et al, 2000; Million Women Study Collaborators, 2003; Beral et al, 2005). The lower RR associated with ET in heavier women can be explained by the elevated endogenous oestrogen level in heavier women, and detailed analysis suggests that the ceiling of effective oestrogen as regards the breast is achieved by women with a BMI of approximately $32 \mathrm{~kg} \mathrm{~m}^{-2}$ (Wu et al, 2007). In the same way, increased oestrogen levels from grapefruit intake may have less and less effect as the 'baseline' oestrogen levels increase. Because the 'baseline' oestrogen level of women on ET or EPT is greater than the effective oestrogen ceiling (Wu et al, 2007), the increased risk from grapefruit intake in these women may be partly a longterm effect of increased progesterone levels in the premenopausal period, but this remains to be studied.

Previous studies have reported that the magnitude of interaction between a drug and grapefruit juice is markedly variable among individuals (Bailey et al, 1993, 1995; Lown et al, 1997; Bailey and Dresser, 2004). Subjects with the highest intestinal expression of CYP3A4 showed the greatest increase in plasma drug concentration of felodipine after grapefruit juice administration (Lown et al, 1997). Currently, there is no way to predict the potential interaction; such studies are urgently needed.

In our study of grapefruit intake and serum oestrogen levels, we observed an approximately $30 \%$ increase in oestrone and a $10 \%$ increase in oestradiol levels among women who consumed the equivalent of $\frac{1}{4}$ grapefruit or more per day. In the present study, we observed a $25-30 \%$ increase in breast cancer risk in the highest category of grapefruit intake. The meta-analysis of the relationship between levels of endogenous sex hormones and breast cancer risk in postmenopausal women by the Endogenous Hormones and Breast Cancer Collaborative Group (Key et al, 2002) found that a doubling of oestradiol was associated with an RR of breast cancer of $1.29(95 \% \mathrm{CI}=1.15-1.44)$. These results suggest that we should have observed a much smaller increase in breast cancer risk in the present study. Even if one uses the $30 \%$ increase in oestrone, then we should have found about a $12 \%$ increase in risk. The reason for the greater breast cancer risk than would be predicted solely on the basis of postmenopausal oestrogen levels may have a number of possible explanations. First, it may be due to chance since the $\mathrm{CI}$ in the present study includes such a value. Second, the estimated $30 \%$ increase in oestrone levels from grapefruit intake may be an underestimate because of misclassification of true dietary intake and because it does not include grapefruit juice. Third, grapefruit may influence oestrogen and progesterone levels in the premenopausal period and the larger effect we see is partly a carry-over effect. Other explanations are possible; more work is certainly needed.

It is biologically plausible that grapefruit intake may increase the risk of breast cancer among postmenopausal women. However, the results of the present study need to be confirmed in other studies with more comprehensive measures of grapefruit intake that include both the whole fruit and grapefruit juice.

\section{ACKNOWLEDGEMENTS}

This work was supported in part by Public Health Service Grant R37 CA54281 from the US National Cancer Institute. All authors contributed to the study design, data analysis, data interpretation, and preparation of the manuscript. The MEC is a collaborative project involving many investigators; as regards to this study, we thank in particular our associate investigators, Dr Lynne Wilkens (University of Hawaii) and Dr Brian Henderson (University of Southern California). 


\section{REFERENCES}

Adlercreutz H (1990) Western diet and Western diseases: some hormonal and biochemical mechanisms and associations. Scand J Clin Lab Invest Suppl 201: 3-23

Arts CJ, Govers CA, van den Berg H, Wolters MG, van Leeuwen P, Thijssen $\mathrm{JH}$ (1991) In vitro binding of estrogens by dietary fiber and the in vivo apparent digestibility tested in pigs. J Steroid Biochem Mol Biol 38: $621-628$

Bailey DG, Arnold JM, Bend JR, Tran LT, Spence JD (1995) Grapefruit juice-felodipine interaction: reproducibility and characterization with the extended release drug formulation. Br J Clin Pharmacol 40: 135-140

Bailey DG, Arnold JM, Munoz C, Spence JD (1993) Grapefruit juicefelodipine interaction: mechanism, predictability, and effect of naringin. Clin Pharmacol Ther 53: 637-642

Bailey DG, Dresser GK (2004) Interactions between grapefruit juice and cardiovascular drugs. Am J Cardiovasc Drugs 4: 281-297

Bailey DG, Spence JD, Edgar B, Bayliff CD, Arnold JM (1989) Ethanol enhances the hemodynamic effects of felodipine. Clin Invest Med 12: $357-362$

Bailey DG, Spence JD, Munoz C, Arnold JM (1991) Interaction of citrus juices with felodipine and nifedipine. Lancet 337: 268-269

Beral V, Reeves G, Banks E (2005) Current evidence about the effect of hormone replacement therapy on the incidence of major conditions in postmenopausal women. Br J Obstet Gynaecol 112: 692-695

Collaborative Group on Hormonal Factors in Breast Cancer (1997) Breast cancer and hormone replacement therapy: collaborative reanalysis of data from 51 epidemiological studies of 52705 women with breast cancer and 108411 women without breast cancer. Lancet 350: 1047 - 1059

Dahan A, Altman H (2004) Food-drug interaction: grapefruit juice augments drug bioavailability - mechanism, extent and relevance. Eur J Clin Nutr 58: 1 -9

Edgar B, Bailey D, Bergstrand R, Johnsson G, Regardh CG (1992) Acute effects of drinking grapefruit juice on the pharmacokinetics and dynamics of felodipine - and its potential clinical relevance. Eur J Clin Pharmacol 42: $313-317$

Englyst HN, Quigley ME, Hudson GJ (1994) Determination of dietary fibre as non-starch polysaccharides with gas-liquid chromatographic, highperformance liquid chromatographic or spectrophotometric measurement of constituent sugars. Analyst 119: $1497-1509$

Goldin BR, Adlercreutz H, Gorbach SL, Warram JH, Dwyer JT, Swenson L, Woods MN (1982) Estrogen excretion patterns and plasma levels in vegetarian and omnivorous women. $N$ Engl J Med 307: $1542-1547$

Goldin BR, Adlercreutz H, Gorbach SL, Woods MN, Dwyer JT, Conlon T, Bohn E, Gershoff SN (1986) The relationship between estrogen levels and diets of Caucasian American and Oriental immigrant women. Am J Clin Nutr 44: $945-953$

Guengerich FP (1999) Cytochrome P-450 3A4: regulation and role in drug metabolism. Annu Rev Pharmacol Toxicol 39: 1-17

Key T, Appleby P, Barnes I, Reeves G (2002) Endogenous sex hormones and breast cancer in postmenopausal women: reanalysis of nine prospective studies. J Natl Cancer Inst 94: 606-616

Kolonel LN, Henderson BE, Hankin JH, Nomura AM, Wilkens LR, Pike MC, Stram DO, Monroe KR, Earle ME, Nagamine FS (2000) A multiethnic cohort in Hawaii and Los Angeles: baseline characteristics [see comments]. Am J Epidemiol 151: 346-357

Lee S, Kolonel L, Wilkens L, Wan P, Henderson B, Pike M (2006) Postmenopausal hormone therapy and breast cancer risk: the Multiethnic Cohort. Int J Cancer 118: 1285-1291

Lown KS, Bailey DG, Fontana RJ, Janardan SK, Adair CH, Fortlage LA, Brown MB, Guo W, Watkins PB (1997) Grapefruit juice increases felodipine oral availability in humans by decreasing intestinal CYP3A protein expression. J Clin Invest 99: 2545-2553

Lundahl J, Regardh CG, Edgar B, Johnsson G (1995) Relationship between time of intake of grapefruit juice and its effect on pharmacokinetics and pharmacodynamics of felodipine in healthy subjects. Eur J Clin Pharmacol 49: $61-67$

Lundahl J, Regardh CG, Edgar B, Johnsson G (1997) Effects of grapefruit juice ingestion - pharmacokinetics and haemodynamics of intravenously and orally administered felodipine in healthy men. Eur J Clin Pharmacol 52: $139-145$

Maskalyk J (2002) Grapefruit juice: potential drug interactions. Can Med Assoc J 167: 279-280

Medical Letter (2005) Drug interactions with grapefruit juice. Obstet Gynecol 105: 429-431

Million Women Study Collaborators (2003) Breast cancer and hormonereplacement therapy in the Million Women Study. Lancet 362: 419-427

Monroe KR, Murphy SP, Henderson BE, Kolonel LN, Stanczyk FZ, Adlercreutz H, Pike MC (2007) Dietary fiber intake \& endogenous serum hormone levels in naturally postmenopausal Mexican-American women: the Multiethnic Cohort Study. Nutr Cancer 58: 1-10

Nothlings U, Wilkens LR, Murphy SP, Hankin JH, Henderson BE, Kolonel LN (2005) Meat and fat intake as risk factors for pancreatic cancer: the multiethnic cohort study. J Natl Cancer Inst 97: 1458-1465

Prentice RL, Caan B, Chlebowski RT, Patterson R, Kuller LH, Ockene JK, Margolis KL, Limacher MC, Manson JE, Parker LM, Paskett E, Phillips L, Robbins J, Rossouw JE, Sarto GE, Shikany JM, Stefanick ML, Thomson CA, Van Horn L, Vitolins MZ, Wactawski-Wende J, Wallace RB, Wassertheil-Smoller S, Whitlock E, Yano K, Adams-Campbell L, Anderson GL, Assaf AR, Beresford SA, Black HR, Brunner RL, Brzyski RG, Ford L, Gass M, Hays J, Heber D, Heiss G, Hendrix SL, Hsia J, Hubbell FA, Jackson RD, Johnson KC, Kotchen JM, LaCroix AZ, Lane DS, Langer RD, Lasser NL, Henderson MM (2006) Low-fat dietary pattern and risk of invasive breast cancer: the Women's Health Initiative Randomized Controlled Dietary Modification Trial. JAMA 295: 629-642

Prosky L, Asp NG, Furda I, DeVries JW, Schweizer TF, Harland BF (1985) Determination of total dietary fiber in foods and food products: collaborative study. J Assoc Off Anal Chem 68: 677-679

Rock CL, Flatt SW, Thomson CA, Stefanick ML, Newman VA, Jones LA, Natarajan L, Ritenbaugh C, Hollenbach KA, Pierce JP, Chang RJ (2004) Effects of a high-fiber, low-fat diet intervention on serum concentrations of reproductive steroid hormones in women with a history of breast cancer. J Clin Oncol 22: 2379-2387

Schairer C, Lubin J, Troisi R, Sturgeon S, Brinton L, Hoover R (2000) Menopausal estrogen and estrogen-progestin replacement therapy and breast cancer risk. JAMA 283: $485-491$

Schubert W, Cullberg G, Edgar B, Hedner T (1994) Inhibition of 17 betaestradiol metabolism by grapefruit juice in ovariectomized women. Maturitas 20: $155-163$

Shultz TD, Howie BJ (1986) In vitro binding of steroid hormones by natural and purified fibers. Nutr Cancer 8: $141-147$

Stram DO, Hankin JH, Wilkens LR, Pike MC, Monroe KR, Park S, Henderson BE, Nomura AM, Earle ME, Nagamine FS, Kolonel LN (2000) Calibration of the dietary questionnaire for a multiethnic cohort in Hawaii and Los Angeles. Am J Epidemiol 151: $358-370$

US Food and Drug Administration (2006) http://www: fda.gov/cder/drug/ infopage/estrogens_progestins/default.htm

van Gils $\mathrm{CH}$, Peeters PH, Bueno-de-Mesquita HB, Boshuizen HC, Lahmann PH, Clavel-Chapelon F, Thiebaut A, Kesse E, Sieri S, Palli D, Tumino R, Panico S, Vineis P, Gonzalez CA, Ardanaz E, Sanchez MJ, Amiano P, Navarro C, Quiros JR, Key TJ, Allen N, Khaw KT, Bingham SA, Psaltopoulou T, Koliva M, Trichopoulou A, Nagel G, Linseisen J, Boeing H, Berglund G, Wirfalt E, Hallmans G, Lenner P, Overvad K, Tjonneland A, Olsen A, Lund E, Engeset D, Alsaker E, Norat T, Kaaks R, Slimani N, Riboli E (2005) Consumption of vegetables and fruits and risk of breast cancer. JAMA 293: 183-193

Veronese ML, Gillen LP, Burke JP, Dorval EP, Hauck WW, Pequignot E, Waldman SA, Greenberg HE (2003) Exposure-dependent inhibition of intestinal and hepatic CYP3A4 in vivo by grapefruit juice. J Clin Pharmacol 43: $831-839$

Willett W (1998) Nutritional epidemiology. Nutritional Epidemilogy Monographs in Epidemiology and Biostatistics; v. 30 New York: Oxford University Press

Wu AH, Pearce CL, Spicer DV, Lee S, Pike MC (2007) Body weight, menopausal hormone therapy, and risk of breast cancer. In: Lobo RA (ed) 3rd edn Treatment of the Postmenopausal Woman: Basic and Clinical Aspects. NY: Academic Press 